\title{
The median local analgesic dose of intrathecal bupivacaine with hydromorphone for labour: a double-blind randomized controlled trial
}

\author{
La dose médiane de bupivacaïne intrathécale avec \\ hydromorphone comme analgésique local pour le travail \\ obstétrical: une étude randomisée contrôlée à double insu
}

\author{
Jill M. Mhyre, MD • Richard W. Hong, MD • \\ Mary Lou V. H. Greenfield, MPH • \\ Nathan L. Pace, MD • Linda S. Polley, MD
}

Received: 19 October 2012/ Accepted: 15 August 2013/Published online: 21 September 2013

(C) Canadian Anesthesiologists' Society 2013

\begin{abstract}
Purpose Neuraxial hydromorphone has been reported to provide rapid onset of labour analgesia, effective segmental pain relief, and a longer duration of action than commonly used lipophilic opioids. This study was conducted to test the hypothesis that intrathecal

Author contributions Jill M. Mhyre, the principal investigator, was responsible for the concept, design, and analysis of the study, and wrote the final manuscript. She had access to all of the data and takes full responsibility for the integrity of the data and the accuracy of the data analysis. Linda S. Polley, Richard W. Hong, and Mary Lou V.H. Greenfield were involved with the design of the study and helped to revise the manuscript prior to submission. Richard W. Hong was involved with drug preparation. Mary Lou Greenfield generated and maintained the randomization records and study assignments and monitored and reported rates of adverse events in compliance with the Institutional Review Board. Nathan L. Pace assisted with data analysis and interpretation and reviewed the final manuscript.
\end{abstract}

Electronic supplementary material The online version of this article (doi:10.1007/s12630-013-0023-7) contains supplementary material, which is available to authorized users.

J. M. Mhyre, MD $(\bowtie) \cdot$ M. L. V. H. Greenfield, MPH ·

L. S. Polley, MD

Department of Anesthesiology, University of Michigan Health System, Room 3622 Neuroscience Hospital, 1500 E. Medical Center Drive SPC 5278, Ann Arbor, MI 48109-5278, USA

e-mail: jmmhyre@med.umich.edu

R. W. Hong, MD

Department of Anesthesiology, University of California Los Angeles, Los Angeles, CA, USA

N. L. Pace, MD

Department of Anesthesiology, University of Utah, Salt Lake City, UT, USA hydromorphone reduces the dose requirement for intrathecal bupivacaine to induce rapid analgesia for women in the first stage of labour.

Methods In this double-blind randomized controlled sequential allocation trial, 88 labouring parturients received combined spinal-epidural analgesia at 2-6 cm cervical dilation. Participants received intrathecal bupivacaine alone or bupivacaine plus hydromorphone $100 \mu \mathrm{g}$ with the bupivacaine dose determined using updown sequential allocation. An effective dose was defined as a visual analogue pain score of $\leq 10 \mathrm{~mm}$ (on a 100-mm pain scale) reported within 20 min of injection. The median effective doses were calculated using the formula of Dixon and Massey and verified using isotonic regression.

Results A decrease was observed in the median local analgesic doses (effective dose [ED50]) estimated according to the formulas of Dixon and Massey, with a between-group difference of $-0.45 \mathrm{mg}$. The precision of the estimate was wide-ranging $195 \%$ confidence interval -1.23 to 0.33), so no definitive conclusion can be drawn. Conclusion Further research is needed to determine whether or not intrathecal hydromorphone $100 \mu \mathrm{g}$ changes the dose of intrathecal bupivacaine required to induce labour analgesia within 20 min.

Trial registration The trial was conducted in 2007 prior to widespread acceptance of the standard for clinical trial registration.

Résumé

Objectif Il a été décrit que l'hydromorphone administrée par voie neuraxiale favorisait l'installation rapide de 
l'analgésie pour le travail obstétrical, un soulagement efficace de la douleur segmentaire, et une durée d'action prolongée comparativement aux opiö̈des lipophiles couramment utilisés. Cette étude a été réalisée afin de tester l'hypothèse selon laquelle l'hydromorphone administrée par voie intrathécale réduirait la dose requise de bupivacaïne intrathécale pour induire une analgésie rapide chez les femmes au premier stade du travail obstétrical.

Méthode Dans cette étude d'attribution séquentielle randomisée contrôlée à double insu, 88 parturientes en travail obstétrical ont reçu une analgésie rachi-péridurale combinée lorsque leur dilatation cervicale était située entre 2 et $6 \mathrm{~cm}$. Les participantes ont reçu de la bupivacaïne intrathécale seule ou de la bupivacaïne avec $100 \mu \mathrm{g}$ d'hydromorphone; la dose de bupivacaïne a été déterminée selon une méthode d'attribution séquentielle verticale (up-down). On a défini la dose efficace comme un score de douleur sur l'échelle visuelle analogique $\leq 10 \mathrm{~mm}$ (sur une échelle de douleur de $100 \mathrm{~mm}$ ) rapporté dans les $20 \mathrm{~min}$ suivant l'injection. Les doses efficaces moyennes ont été calculées à l'aide de la formule de Dixon et Massey et vérifiées par régression isotonique.

Résultats Une réduction a été observée dans les doses moyennes d'analgésique local (dose efficace [DE50]) estimées selon la formule de Dixon et Massey, et une différence de $-0,45 \mathrm{mg}$ a été observée entre les groupes. La précision de cet estimé était faible (intervalle de confiance $95 \%-1,23$ à 0,33); par conséquent, aucune conclusion définitive n'a pu être tirée.

Conclusion Des recherches supplémentaires sont nécessaires afin de déterminer si l'administration de $100 \mu \mathrm{g}$ d'hydromorphone intrathécale modifie la dose de bupivacaïne intrathécale nécessaire à induire l'analgésie du travail obstétrical en 20 minutes.

Enregistrement de l'étude Cette étude a été réalisée en 2007, soit avant que l'enregistrement des études cliniques ne soit devenu la norme acceptée.

Lipophilic opioids, such as fentanyl and sufentanil, play an important role in contemporary neuraxial labour analgesia. Nevertheless, high lipid solubility increases systemic absorption and reduces bioavailability in the dorsal horn of the spinal cord. ${ }^{1}$ The hydrophilic opioid, hydromorphone, has been proposed as an alternative that may offer enhanced bioavailability and result in a more favourable ratio of analgesia to side effects when compared with lipophilic fentanyl or sufentanil. In previous clinical studies, spinal or epidural hydromorphone in combination with bupivacaine has been reported to have relatively quick onset (5-20 $\mathrm{min})^{2, \mathrm{~A}}$ and to deliver primarily segmental analgesia with high analgesic potency. ${ }^{3}$ These trials employed a relatively high dose of bupivacaine $(2.5 \mathrm{mg}$ in the spinal space ${ }^{\mathrm{A}}$ or $8-10 \mathrm{~mL}$ of a $0.25 \%$ solution in the epidural space $)^{2}$; therefore, it is not clear if the rapid onset was a function of the hydromorphone or the coadministered bupivacaine.

We designed this randomized double-blind sequential allocation study to test the hypothesis that intrathecal hydromorphone reduces the dose requirement for intrathecal bupivacaine to achieve rapid analgesia for women in the first stage of labour. Our primary outcome was the median effective dose (ED50) of intrathecal bupivacaine. Specifically, a statistically significant decrease in the ED50 of intrathecal bupivacaine-also known as the minimum local anesthetic dose-in the presence of co-administered hydromorphone $100 \mu \mathrm{g}$ would indicate a dose-sparing effect when compared with bupivacaine alone. Secondary outcomes included potential side effects of intrathecal hydromorphone, including nausea, itching, sedation, bradypnea, or nonreassuring fetal heart rate patterns.

\section{Methods}

The study was approved by the Institutional Review Board of the University of Michigan Medical School (HUM\#00010064, approved January 11, 2007) and was funded by the Department of Anesthesiology. All patients were recruited at the time of admission for labour and delivery and gave written informed consent. We included American Society of Anesthesiologists physical status I and II women with singleton term pregnancies (> 36 weeks' gestation), vertex fetal presentation, and in active labour who anticipated neuraxial analgesia and vaginal delivery. Exclusion criteria included difficulty understanding English, contraindications to neuraxial analgesia, allergy to bupivacaine or hydromorphone, severe preeclampsia, known fetal abnormality, and a body mass index $>40$. A research assistant screened potential subjects at the time of admission and recruited those meeting eligibility criteria. We enrolled and randomized patients at the time of neuraxial block placement after excluding those patients with a visual analogue pain score $<50 \mathrm{~mm}$ (on a $100-\mathrm{mm}$ pain scale),

\footnotetext{
$\overline{\text { A Tiouririne }} M$, Holiday J, Durieux M, Wheeler A. Duration of intrathecal hydromorphone for labor analgesia. Anesthesiology 2006; 105: A915.
} 
cervical dilation $>7 \mathrm{~cm}$, or opioid medication administered within the previous two hours. All studyrelated procedures took place on the University of Michigan Labour and Delivery Unit.

Participants were randomized to receive either intrathecal bupivacaine (bupivacaine hydrochloride; Hospira, Inc., Lake Forest, IL, USA) alone or intrathecal bupivacaine in combination with hydromorphone $100 \mu \mathrm{g}$ (hydromorphone hydrochloride; Hospira, Inc., Lake Forest, IL, USA). The hydromorphone dose was based on an observational trial in which the combination of intrathecal bupivacaine $1.3 \mathrm{mg}$ and hydromorphone $100 \mu \mathrm{g}$ provided effective labour analgesia within seven minutes with minimal side effects. ${ }^{A}$ The first patient studied in each group received bupivacaine $2.5 \mathrm{mg}$, and thereafter, the dose of bupivacaine in each individual syringe was determined by the response of the previous patient in that group according to up-down sequential allocation. The testing interval was bupivacaine $0.25 \mathrm{mg}$ for all groups. ${ }^{4}$

An investigator with no other study responsibilities (M.G.) implemented a simple randomization scheme in Excel by generating the sequence 1-100 and assigning the numbers 1-50 to control and 51-100 to hydromorphone. The order of the numbers was then randomized using Excel's RAND function to produce the treatment allocation sequence, which was maintained on a secure network drive. This investigator recorded patient outcomes, as reported by the investigator responsible for data interpretation (L.P.), tracked and reported adverse events to the Institutional Review Board, and used the allocation sequence and prior subject outcomes to assign the group (hydromorphone or control) and dose of bupivacaine for each upcoming patient. Two anesthesiologists not involved in recruitment, data collection, or direct patient care (J.M. and R.H.) prepared syringes of the blinded study solution within $30 \mathrm{hr}$ of administration using preservative-free normal saline, $0.25 \% \mathrm{wt} / \mathrm{vol}$ plain bupivacaine and preservative-free hydromorphone to achieve the desired doses of bupivacaine and hydromorphone at room temperature $\left(20^{\circ} \mathrm{C}\right)$ in a standardized volume of $2.5 \mathrm{~mL}$. Study patients, physicians and nurses, and research assistants responsible for recruitment, enrolment, and study implementation were unaware of treatment assignments at any time during the study. Study coordination is illustrated in the Appendix as Electronic Supplementary Material.

Study medications were administered using a combined spinal-epidural technique. After intravenous prehydration with lactated Ringer's solution 500-1000 mL, patients were placed in the flexed sitting position. After raising a midline wheal with $1.0 \% \mathrm{wt} / \mathrm{vol}$ lidocaine, the epidural space was identified using an 18-G Tuohy needle with loss of resistance to saline (1-5 mL) at L2-3 or L3-4. A $25-\mathrm{G}$ 119-mm Whitacre spinal needle was placed through the Tuohy needle at a depth sufficient to puncture the dura mater and obtain cerebrospinal fluid. The study drug solution was then injected in a $2.5 \mathrm{~mL}$ volume. After the Whitacre needle was withdrawn, a three-hole polyamide catheter (Portex $^{\mathrm{TM}}$, Smiths Medical, London, UK) was advanced $4-5 \mathrm{~cm}$ into the epidural space in a cephalad direction for subsequent epidural labour analgesia. The epidural catheter was secured using a sterile transparent occlusive dressing at the skin. Catheter placement was confirmed using aspiration. A test dose of lidocaine with epinephrine was deferred until study data had been collected. After catheter placement, the parturient was placed in the supine position with left uterine displacement and $30^{\circ}$ elevation of the head of the bed. Time zero was defined as the end of the intrathecal injection.

The efficacy of the study drug was assessed by the patient using a $100-\mathrm{mm}$ vertical visual analogue pain scale (VAPS) with the anchors "no pain" and "worst pain ever." The VAPS was recorded at five-minute intervals for 20 min following intrathecal injection.

An effective dose, defined as a VAPS $\leq 10 \mathrm{~mm}$ within 20 min of injection ${ }^{4-7}$ directed a decrement of bupivacaine $0.25 \mathrm{mg}$ for the next patient randomized to that group. The duration of effective spinal analgesia (defined as the time interval from the intrathecal injection to the time when the parturient experienced her first painful contraction) was recorded. At that time, the patient received a standard epidural test dose of $1.5 \%$ lidocaine $3 \mathrm{~mL}$ with epinephrine 1:200,000 followed by a bolus and infusion of $0.05 \%$ bupivacaine with fentanyl $3 \mu \mathrm{g} \cdot \mathrm{mL}^{-1}$. Subsequent epidural catheter management was at the discretion of the clinical care team. An ineffective dose was defined as a VAPS $>10 \mathrm{~mm}$ at 20 min after injection, with pain located within the T8-L5 dermatomes. An ineffective result directed an increase of bupivacaine $0.25 \mathrm{mg}$ for the next patient randomized to that group. The trial was rejected if the spinal space could not be identified, if the patient progressed to the second stage of labour in $<60 \mathrm{~min}$, if the source of pain underlying a VAPS $>10 \mathrm{~mm}$ originated outside the T8-L5 dermatome, or in cases of protocol violations. When the trial was rejected, the same dose of bupivacaine was repeated for the next participant randomized to the same group. In cases where the trial was ineffective or rejected, the epidural catheter was dosed as described above after $20 \mathrm{~min}$.

The following data were recorded for all women at the time of combined spinal-epidural insertion: age, weight, height, ethnicity, gestational weeks, parity, cervical dilation, membrane status (spontaneously ruptured, artificially ruptured, or intact), the use of pharmacologic agents to induce or to augment labour (including oxytocin, vaginal misoprostol, vaginal dinoprostone, and vaginal laminaria), baseline maternal and fetal vital signs (blood pressure, heart 
rate, respiratory rate, and cardiotocography), maternal pain, nausea (measured using a $100-\mathrm{mm}$ visual analogue scale [VAS] with the anchors "no nausea" and "the most severe nausea you can imagine"), pruritus (measured using a 100-mm VAS with the anchors "no pruritus" and "the most severe pruritus you can imagine"), and maternal sedation (assessed by any decrease in response to verbal stimulation).

After intrathecal injection, maternal monitoring included blood pressure, heart rate, and pulse oximetry measurements every five minutes during the first $20 \mathrm{~min}$ and again at $30 \mathrm{~min}$. Hypotension was defined as a systolic blood pressure $<100 \mathrm{mmHg}$ or a $20 \%$ fall below the baseline recording. Hypotension was treated with ephedrine $5 \mathrm{mg}$ with additional doses as required and intravenous fluid boluses. The VAPS was measured every five minutes during the first $20 \mathrm{~min}$ for all patients and then at 60 and $120 \mathrm{~min}$ for women with effective analgesia. Sensation to pinprick using a Neuropen ${ }^{\circledR}$ (Owen Mumford Ltd, Woodstock, UK) was measured at $20 \mathrm{~min}$ and again at 60 and $120 \mathrm{~min}$. Additional measurements at 20, 60, and 120 min included the presence of motor block, ${ }^{8}$ and the presence and severity of nausea, pruritus, and sedation, assessed as described above. ${ }^{9}$ The fetal heart rate was continuously monitored by cardiotocography, and adverse events documented by the clinical care team were recorded. The date, time, and mode of delivery, and any indication for Cesarean delivery were also recorded.

\section{Statistical analysis}

All analyses were conducted using included patients only. The distributions of continuous data were visually inspected. Continuous data were summarized as mean (SD) or median (interquartile range [IQR]) if the data were skewed, and categorical data were presented as counts with frequencies. Side effects, including nausea, pruritus, and sedation, were presented as the proportion of women who experienced any measured effect at any of the three time points (20,60, and $120 \mathrm{~min})$.

For each group, an estimate of ED50 and the standard error of the estimate were determined from the up-down sequences using the formula of Dixon and Massey. ${ }^{10}$ The two-sample Student's $t$ test with unequal variances was used to compare these estimates and to generate the $95 \%$ confidence interval (CI) for the difference in means.

The technique of isotonic regression was used to confirm the ED50 for each group. Pace and Stylianou ${ }^{11}$ introduced this analytic method to minimize reliance on unverifiable assumptions save for the assumption that drug effect increases as dose increases in a monotonic fashion. First, an adjusted response probability was calculated using the pooled adjusted violations algorithm. Second, a nonparametric isotonic regression estimator of ED50 was calculated, and the 95\% CI was obtained using a parametric bootstrap routine. ${ }^{11}$ Third, the bootstrap sampling distributions for the control and hydromorphone group were used jointly to estimate the $95 \%$ CI for the between-group difference in ED50.

To illustrate the change in pain score over time in each group, serial two-sided Student's $t$ tests were used to calculate the $95 \%$ CI for the between-group difference in mean pain score measured for each group at each time.

The duration of effective analgesia was compared using the between-group difference in median durations, with the Bonett-Price 95\% CI calculated by applying the bpdifmed command in Stata.

Isotonic regression estimation was performed in the boot package 1.3-9 running under R 3.0.1 (R Foundation for Statistical Computing, Vienna, Austria) using previously reported functions. ${ }^{11}$ All other analyses were completed with Microsoft Excel 5.0 for Windows and Stata 12.0 (Stata Corps, College Town, TX, USA). All reported $P$ values are two-sided and declared significant if $P \leq 0.05$.

Sample size estimations are based on a previous up-down sequential allocation study of intrathecal bupivacaine with varying doses of fentanyl in which the median (SD) local anesthetic dose of plain bupivacaine was estimated to be 1.99 (0.486) mg. ${ }^{4}$ Using the two-sided Student's $t$ test with an estimated standard deviation of $0.486 \mathrm{mg}$ and assuming equal variance between groups, 15 patients per group were required to estimate a $25 \%$ difference $\geq 0.5 \mathrm{mg}$ at alpha $=0.05$ (two-sided), with power of 0.8. Estimations of the ED50 and 95\% CIs using the formula of Dixon and Massey are based on the sequence of successful or failed doses, whichever series includes fewer observations; ${ }^{12}$ therefore, recruitment continued until a minimum number of 15 effective and ineffective outcomes were recorded for each group.

\section{Results}

Eighty-eight women met inclusion criteria and were randomized from January 30, 2007 through November 28, 2007 (Fig. 1). Twenty-one women were excluded after randomization. No differences in demographic or obstetric characteristics were noted between groups (Table 1). No participants experienced pruritus at baseline.

A decrease in the median dose of local analgesic (ED50) was observed, as estimated according to the formulas of Dixon and Massey (hydromorphone ED50, $2.16 \mathrm{mg}$; standard error [SE] 0.11 vs control ED50, $2.61 \mathrm{mg}$; SE 0.37) (Figs. 2a, 2b), with an observed between-group difference of $-0.45 \mathrm{mg} \quad(95 \%$ CI -1.23 to 0.33$)$. Nevertheless, the range of observed bupivacaine doses 


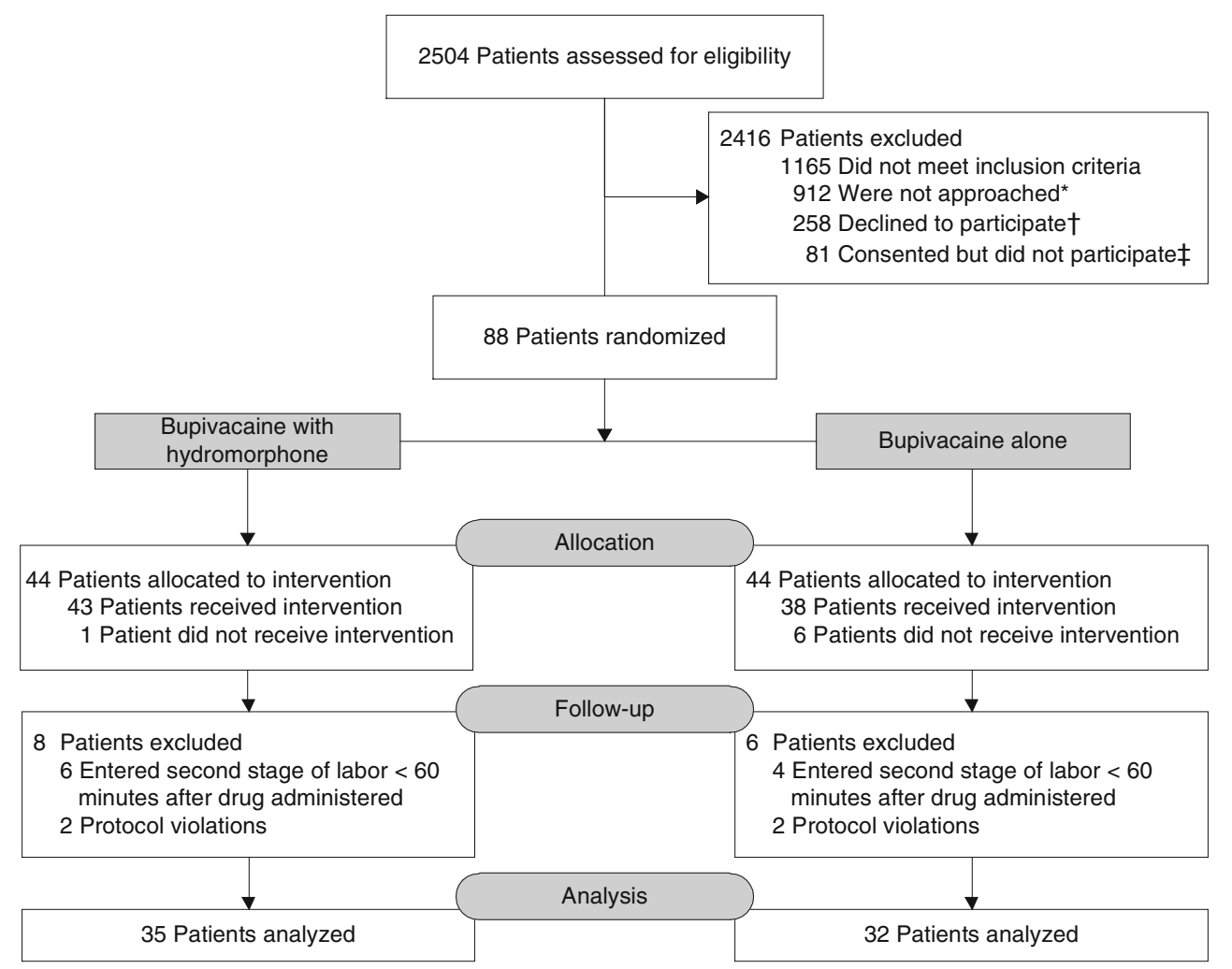

Fig. 1 Patient assessment, randomization, allocation, follow-up, and analysis for the trial. *The chief reasons for not approaching potential study participants were: (1) no research assistants were available on the weekend shifts; (2) the patient was sleeping; or (3) the patient had a rapid delivery before she could be approached. ${ }^{\dagger}$ The chief reasons that patients gave for declining to participate in the study were: (1) the patient was unwilling or uninterested in being in a study; or (2) she was not planning to have epidural analgesia. ${ }^{+}$The chief reasons why

Table 1 Patient demographics and baseline characteristics

\begin{tabular}{lll}
\hline Characteristic & $\begin{array}{l}\text { Hydromorphone } \\
(n=35)\end{array}$ & $\begin{array}{l}\text { Control } \\
(n=32)\end{array}$ \\
\hline Age (yr) & $28.6(5.1)$ & $28.6(5.3)$ \\
Race/ethnicity & $27(77.2 \%)$ & $24(75.0 \%)$ \\
White & $5(14.3 \%)$ & $4(12.5 \%)$ \\
Black & $3(8.6 \%)$ & $4(12.5 \%)$ \\
Other & $30.1(4.6)$ & $31.2(4.8)$ \\
Body mass index $\left(\mathrm{kg} \cdot \mathrm{m}^{-2}\right)$ & & $16(50.0 \%)$ \\
Parity & $9(25.7 \%)$ & $8(25.0 \%)$ \\
Nulliparous & $17(48.5 \%)$ & $8(25.0 \%)$ \\
Primiparous & $9(25.7 \%)$ & $39.3(1.3)$ \\
Multiparous & $39.2(1.2)$ & $4.4(1.2)$ \\
Gestational age (weeks) & $4.1(1.2)$ & $77.1(14.0)$ \\
Cervical dilation (cm) & $80.9(15.3)$ & $5(15.6 \%)$ \\
Baseline visual analogue pain score & $1(2.9 \%)$ & 0 \\
Any baseline nausea & $1(2.9 \%)$ & \\
Any baseline sedation &
\end{tabular}

Data are mean (standard deviation), frequencies (\%). No participant experienced pruritus at baseline patients who consented to be in the study did not participate were: (1) at the time of the patient's request for epidural analgesia, she no longer met study inclusion criteria (e.g., an opioid had been given $<$ two hours before epidural; cervical dilation was $>7 \mathrm{~cm}$; visual analogue pain scale was $<50 \mathrm{~mm}$ ); or (2) the patient received epidural analgesia when research assistants were not available (e.g., the research assistant was with another study patient, not working, on weekends and night shifts)

(control group: 1.75-3.50 mg, eight dose levels; hydromorphone group: $1.50-2.75 \mathrm{mg}$, six dose levels) resulted in an imprecise estimate of the treatment effect, and no definitive conclusion can be drawn. As a sensitivity analysis, similar results were shown by using the isotonic regression estimator and bias corrected bootstrapping to calculate the $95 \%$ CIs of each ED50 and the difference in ED50s (data not shown).

Based on visual inspection, the onset of analgesia appeared to be more gradual in the hydromorphone group (Fig. 3). Repeated measures analysis of variance confirmed a significant treatment-by-time interaction over the first 20 min after spinal injection $(P=0.03)$. Table 2 lists the mean VAPS for each group, the observed difference between groups, and the $95 \%$ confidence interval for the between-group difference.

The median duration of effective analgesia was not significantly different between groups (hydromorphone: 88 min, IQR [58,146] vs control: 55 min, IQR [45,73]) based on the difference of 33 min in median duration of effective analgesia (95\% CI -9.0 to $75.0 ; P=0.12$ ). 
Fig. 2 (a) Bupivacaine control; (b) Bupivacaine with hydromorphone. The up-down sequences of the administered dose of bupivacaine and the results obtained in the presence (Fig. 2a) and absence (Fig. 2b) of co-administered hydromorphone. Horizontal lines represent the effective dose (ED) 50 calculated using the formula of Dixon and Massey. Error bars represent the 95\% confidence interval for each ED50 estimate (a)

Bupivacaine (Control)

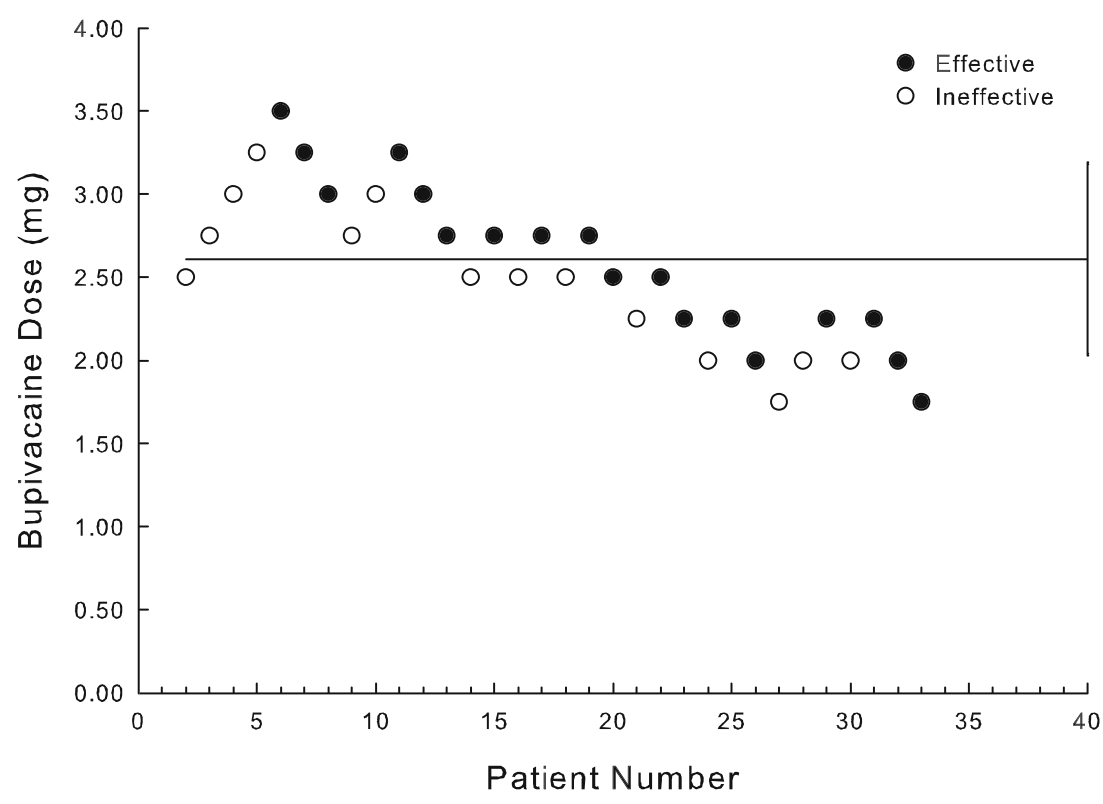

(b)

Bupivacaine with Hydromorphone

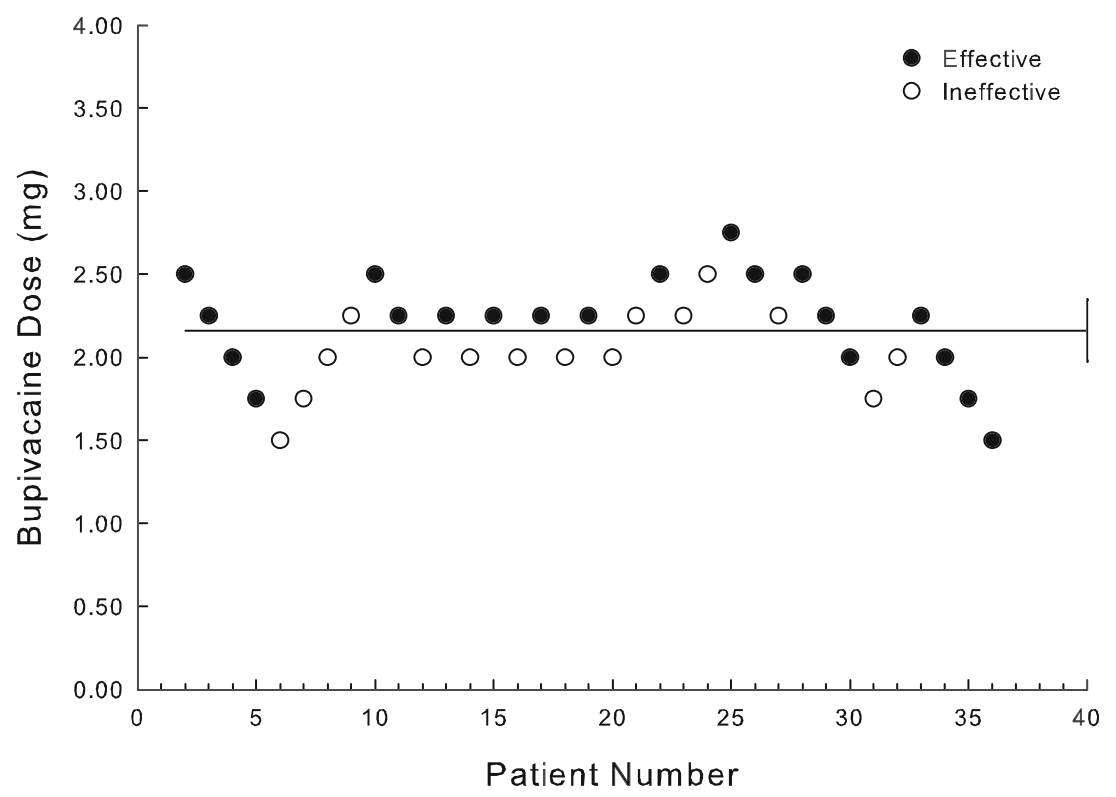

Block height at $20 \mathrm{~min}$, pruritus, nausea, sedation, hypotension, and mode of delivery are presented in Table 3.

Two patients randomized to the hydromorphone group experienced clinically significant non-reassuring fetal heart rate tracings within $30 \mathrm{~min}$ of receiving the study drug. One woman experienced rapid dilation to $10 \mathrm{~cm}$ and delivered vaginally with vacuum assistance. A second woman experienced fetal heart rate decelerations in the context of maternal hypotension within $15 \mathrm{~min}$ of receiving the study drug; however, this resolved after ephedrine was administered. There were no complications or adverse sequelae in either the mothers or their babies following these events, and all were discharged home within three days of delivery.

\section{Discussion}

Epidural hydromorphone has been reported to provide rapid and effective neuraxial analgesia with minimal side effects. ${ }^{3}$ An analgesic onset of less than ten minutes was 


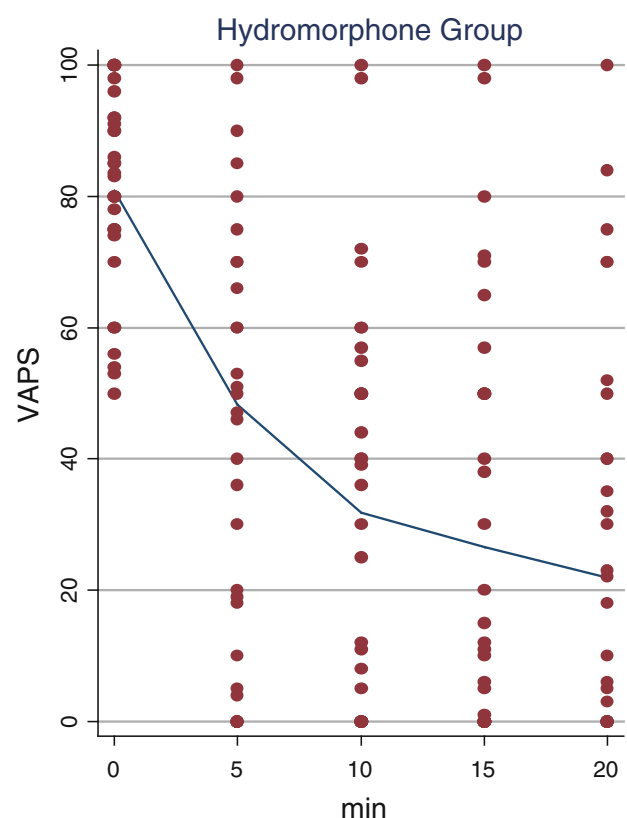

Fig. 3 Visual analogue pain score (VAPS) following intrathecal dosing. The serial VAPS measurements are shown for all included participants over the first $20 \mathrm{~min}$ regardless whether the dose was considered effective or ineffective. The two lines are projected with

Table 2 The visual analogue pain scores measured by group and between-group differences at each time point during the first $20 \mathrm{~min}$ after intrathecal drug administration

\begin{tabular}{llll}
\hline Variable & $\begin{array}{l}\text { Hydromorphone } \\
n=35 \\
\text { Mean (SD) }\end{array}$ & $\begin{array}{l}\text { Control } \\
n=32 \\
\text { Mean (SD) }\end{array}$ & $\begin{array}{l}\text { Between group } \\
\text { difference }(95 \% \text { CI) }\end{array}$ \\
\hline $\begin{array}{l}\text { Pre- } \\
\text { procedural } \\
\text { VAPS }\end{array}$ & $80.9(15.3)$ & $77.1(14.0)$ & $3.8(-3.4$ to 11.0$)$ \\
$\begin{array}{l}\text { VAPS at } \\
5 \text { min }\end{array}$ & $37.7(33.6)$ & $23.5(29.1)$ & $14.2(-1.6$ to 30.0$)$ \\
$\begin{array}{l}\text { VAPS at } \\
10 \text { min }\end{array}$ & $31.2(30.1)$ & $16(25.9)$ & $15.2(1.4$ to 29.0$)$ \\
$\begin{array}{l}\text { VAPS at } \\
15 \text { min }\end{array}$ & $26.5(31.5)$ & $17.9(28.8)$ & $8.7(-6.2$ to 23.6) \\
$\begin{array}{l}\text { VAPS at } \\
20 \text { min }\end{array}$ & $21.9(29.1)$ & $23.3(30.5)$ & $-1.4(-15.9$ to 13.1$)$ \\
\hline
\end{tabular}

$\mathrm{CI}=$ confidence interval; $\mathrm{VAPS}=$ visual analogue pain score

reported in an observational review of 1,830 labouring parturients treated with epidural hydromorphone $100 \mu \mathrm{g}$, but the hydromorphone was dosed in conjunction with $0.25 \%$ bupivacaine $8-10 \mathrm{~mL}$ with epinephrine $1: 200,000 .^{2}$ Likewise, a randomized controlled trial compared epidural fentanyl $100 \mu \mathrm{g}$ with and without co-administered hydromorphone $300 \mu \mathrm{g}$ when administered following a pharmacologic test dose with $1.5 \%$ lidocaine $3 \mathrm{~mL}$ with epinephrine $1: 200,000 ;{ }^{13}$ the median VAPS in both groups fell at least $69 \%$ within ten minutes. Studies of intrathecal

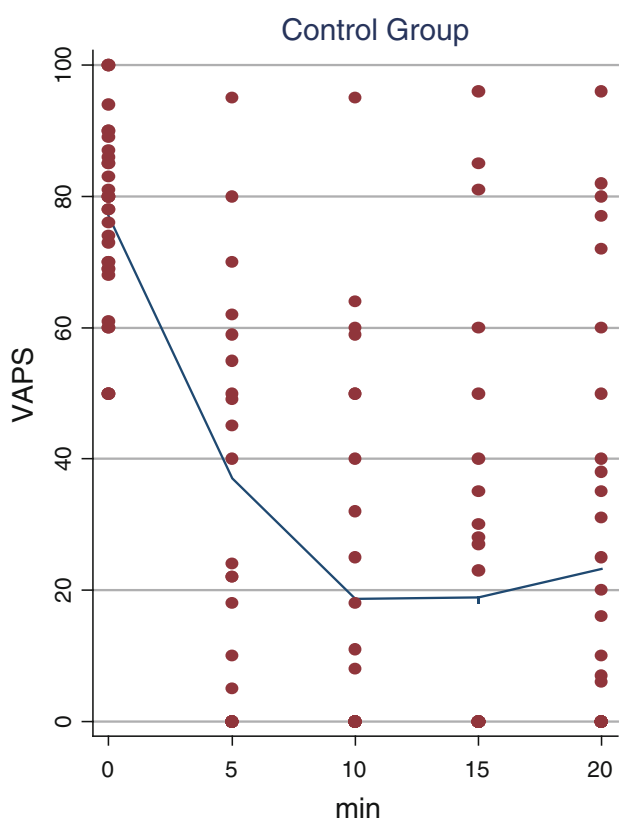

the locally weighted scatterplot smoothing (LOWESS) function using maximum likelihood estimation. VAPS $=$ visual analogue pain score (on a scale of 0-100 $\mathrm{mm}$ )

Table 3 Mode of delivery, sensory level, and side effects

\begin{tabular}{|c|c|c|}
\hline Characteristic & $\begin{array}{l}\text { Hydromorphone } \\
(n=35)\end{array}$ & $\begin{array}{l}\text { Control } \\
(n=32)\end{array}$ \\
\hline \multicolumn{3}{|l|}{ Mode of delivery } \\
\hline Spontaneous vaginal delivery & $31(88.6 \%)$ & $29(90.6 \%)$ \\
\hline $\begin{array}{l}\text { Vacuum-assisted vaginal } \\
\text { delivery }\end{array}$ & $3(8.6 \%)$ & $1(3.1 \%)$ \\
\hline Cesarean delivery & $1(2.9 \%)$ & $2(6.3 \%)$ \\
\hline $\begin{array}{l}\text { Sensory level to Neuropen }{ }^{\circledR} \text { at } \\
20 \mathrm{~min}\end{array}$ & T9 [T8,T11] & $\mathrm{T} 10[\mathrm{~T} 8, \mathrm{~T} 11]$ \\
\hline Hypotension within $20 \mathrm{~min}$ & $6(17.1 \%)$ & $14(43.8 \%)$ \\
\hline Pruritus within $2 \mathrm{hr}$ & $11(31.4 \%)$ & $4(12.5 \%)$ \\
\hline Nausea within $2 \mathrm{hr}$ & $9(25.7 \%)$ & $4(12.5 \%)$ \\
\hline Sedation within $2 \mathrm{hr}$ & $10(28.6 \%)$ & $9(28.1 \%)$ \\
\hline
\end{tabular}

Data are count $(\%)$ or median [interquartile range]

Nausea, pruritus, and sedation are presented as the proportion of women who experienced any measured effect at any of the three time points $(20,60$, or $120 \mathrm{~min})$

hydromorphone for labour analgesia report a similar rapid onset. $^{\mathrm{A}}$

Physiologic explanations for the relatively rapid onset observed in these studies and in clinical practice usually rest on the intermediate lipophilicity of hydromorphone. Hydromorphone has an octanol/buffer coefficient of 1.111.35 , which is comparable with morphine (0.70-1.39) and much less than fentanyl (688-724) or sufentanil (17002842). ${ }^{14,15}$ It is debatable whether a small increase in lipophilicity relative to morphine is present and clinically 
significant. $^{16,17}$ An alternate explanation is that coadministration with local anesthetic, epinephrine, or a lipophilic opioid may have helped to facilitate rapid analgesic onset. ${ }^{2, \mathrm{~A}, 13}$

Although the current study was designed to test whether intrathecal hydromorphone $100 \mu \mathrm{g}$ changes the dose of intrathecal bupivacaine required to induce effective labour analgesia within $20 \mathrm{~min}$, the study results are inconclusive. While the observed difference in intrathecal doses of bupivacaine was $0.45 \mathrm{mg}$, the $95 \%$ CI ranges from a $1.23 \mathrm{mg}$ decrease in dose to a $0.33 \mathrm{mg}$ increase in dose; this range includes clinically important differences.

Hydromorphone is not licensed for intrathecal or epidural use and is rated as Pregnancy Category $\mathrm{C}$ by the United States Food and Drug Administration. ${ }^{18}$ There is a lack of adequate and well-controlled studies in pregnant women, and the effect of hydromorphone, if any, on the later growth, development, and functional maturation of the child is unknown. According to the package insert, hydromorphone should be used during pregnancy, labour, and delivery, or in nursing mothers only if the potential benefit justifies the potential risk to the fetus or newborn. Nevertheless, intrathecal hydromorphone has been used safely for women in labour, ${ }^{\mathrm{A}}$ and epidural hydromorphone has been used for women in labour and following Cesarean delivery. ${ }^{2,19-24}$ There have been no reports of delayed respiratory depression in obstetric patients with epidural or intrathecal hydromorphone. ${ }^{3}$ Intrathecal hydromorphone $100 \mu \mathrm{g}$ induces an equianalgesic response to approximately $250-500 \mu \mathrm{g}$ of intrathecal morphine, ${ }^{25,26}$ with a lower incidence of side effects, including nausea, vomiting, pruritus, urinary retention, and sedation. ${ }^{26}$ An increasing number of papers describe safe administration of long-term intrathecal hydromorphone for chronic pain, ${ }^{26,27}$ and hydromorphone is now listed with morphine as a first-line agent for intrathecal administration in chronic pain patients. ${ }^{28}$

The current study is limited by a number of factors. The small sample size resulted in an imprecise estimate of the treatment effect; hence, no definitive conclusion can be drawn. Analgesic outcome was determined at $20 \mathrm{~min}$; however, a longer study period may have revealed a significant local anesthetic dose-sparing effect. Hydromorphone $100 \mu \mathrm{g}$ was not compared with other doses to determine a dose-response effect or with other opioids to determine potency ratios or relative frequency of side effects. This study targeted the ED50 to minimize the contribution of local anesthetic to any resulting analgesia; therefore, the study results may not apply at the ED95. Fourteen patients were excluded from analysis after receiving the randomized treatment, including ten who delivered within $60 \mathrm{~min}$ of the spinal dose. This was a practical consideration that allowed the recruitment team to assure prospective participants that they would not be required to participate in active study assessments during the second stage of labour. It is not possible to perform a retrospective intent-to-treat analysis because case exclusions resulted in alterations in the dose sequence. The study was not designed to identify differences in rates of hypotension, pruritus, nausea, sedation, or operative delivery; but events were tabulated so they may be combined with future study results. Likewise, this study was not designed to test the hypothesis that intrathecal hydromorphone could prolong the duration of effective intrathecal labour analgesia. Future research is needed to explore the utility of hydromorphone as an adjuvant for maintenance of neuraxial analgesia.

In conclusion, further research is needed to determine whether or not intrathecal hydromorphone $100 \mu \mathrm{g}$ changes the dose of intrathecal bupivacaine required to induce labour analgesia within $20 \mathrm{~min}$.

Acknowledgements We acknowledge the work of our research assistants, Michael Plakke, Heiry Choi, and Daniel Axelson, and the advice of Kathy Welch and David Childers from the University of Michigan Center for Statistical Consultation and Research.

Conflicts of interest None declared.

Funding source Internal funding was provided by: Department of Anesthesiology, The University of Michigan Health System, Ann Arbor, MI 48109-5278, USA.

\section{References}

1. Bernards $C M$. Recent insights into the pharmacokinetics of spinal opioids and the relevance to opioid selection. Curr Opin Anaesthesiol 2004; 17: 441-7.

2. Sinatra RS, Eige S, Chung JH, et al. Continuous epidural infusion of $0.05 \%$ bupivacaine plus hydromorphone for labor analgesia: an observational assessment in 1830 parturients. Anesth Analg 2002; 94: 1310-1.

3. Sinatra RS, Levin S, Ocampo CA. Neuroaxial hydromorphone for control of postsurgical, obstetric, and chronic pain. Semin Anesth Periop Med Pain 2000; 19: 108-31.

4. Stocks GM, Hallworth SP, Fernando R, England AJ, Columb $M O$, Lyons $G$. Minimum local analgesic dose of intrathecal bupivacaine in labor and the effect of intrathecal fentanyl. Anesthesiology 2001; 94: 593-8.

5. Camorcia M, Capogna $G$, Columb MO. Minimum local analgesic doses of ropivacaine, levobupivacaine, and bupivacaine for intrathecal labor analgesia. Anesthesiology 2005; 102: 646-50.

6. Sia AT, Goy $R W$, Lim Y, Ocampo CE. A comparison of median effective doses of intrathecal levobupivacaine and ropivacaine for labor analgesia. Anesthesiology 2005; 102: 651-6.

7. Whitty R, Goldszmidt E, Parkes RK, Carvalho JC. Determination of the ED95 for intrathecal plain bupivacaine combined with fentanyl in active labor. Int J Obstet Anesth 2007; 16: 341-5.

8. Breen TW, Shapiro T, Glass B, Foster-Payne D, Oriol NE. Epidural anesthesia for labor in an ambulatory patient. Anesth Analg 1993; 77: 919-24.

9. Chernik DA, Gillings D, Laine $H$, et al. Validity and reliability of the Observer's Assessment of Alertness/Sedation Scale: study 
with intravenous midazolam. J Clin Psychopharmacol 1990; 10: 244-51.

10. Dixon WJ, Massey FJ. Sensitivity experiments. In: Dixon W, Massey FJ, editors. Introduction to Statistical Analysis - Fourth Edition. New York: McGraw Hill Book Co.; 1983. p. 426-41.

11. Pace NL, Stylianou MP. Advances in and limitations of up-anddown methodology: a precis of clinical use, study design, and dose estimation in anesthesia research. Anesthesiology 2007; 107: 144-52.

12. Polley LS, Columb MO, Wagner DS, Naughton NN. Dosedependent reduction of the minimum local analgesic concentration of bupivacaine by sufentanil for epidural analgesia in labor. Anesthesiology 1998; 89: 626-32.

13. Parker RK, Connelly NR, Lucas T, et al. The addition of hydromorphone to epidural fentanyl does not affect analgesia in early labour. Can J Anesth 2002; 49: 600-4.

14. Plummer JL, Cmielewski PL, Reynolds GD, Gourlay GK, Cherry $D A$. Influence of polarity on dose-response relationships of intrathecal opioids in rats. Pain 1990; 40: 339-47.

15. Roy SD, Flynn GL. Solubility and related physicochemical properties of narcotic analgesics. Pharm Res 1988; 5: 580-6.

16. Boswell $M V$. Lipid solubility and epidural opioid efficacy. Anesthesiology 1995; 83: 427-8.

17. Liu S, Carpenter RL, Mulroy MF, et al. Intravenous versus epidural administration of hydromorphone. Effects on analgesia and recovery after radical retropubic prostatectomy. Anesthesiology 1995; 82: 682-8.

18. U.S. Food and Drug Administration. Drugs@FDA: FDA Approved Drug Products. Available from URL: http://www. accessdata.fda.gov/scripts/cder/drugsatfda/ (accessed June 2013).

19. Chaplan SR, Duncan SR, Brodsky JB, Brose WG. Morphine and hydromorphone epidural analgesia. A prospective, randomized comparison. Anesthesiology 1992; 77: 1090-4.
20. Chestnut DH, Choi WW, Isbell TJ. Epidural hydromorphone for postcesarean analgesia. Obstet Gynecol 1986; 68: 65-9.

21. Dougherty TB, Baysinger CL, Henenberger JC, Gooding DJ. Epidural hydromorphone with and without epinephrine for postoperative analgesia after cesarean delivery. Anesth Analg 1989; 68: $318-22$

22. Halpern SH, Arellano $R$, Preston $R$, et al. Epidural morphine vs hydromorphone in post-caesarean section patients. Can J Anaesth 1996; 43: 595-8.

23. Henderson SK, Matthew EB, Cohen H, Avram MJ. Epidural hydromorphone: a double-blind comparison with intramuscular hydromorphone for postcesarean section analgesia. Anesthesiology 1987; 66: 825-30.

24. Parker RK, White $P F$. Epidural patient-controlled analgesia: an alternative to intravenous patient-controlled analgesia for pain relief after cesarean delivery. Anesth Analg 1992; 75: 245-51.

25. Johansen MJ, Satterfield WC, Baze WB, Hildebrand KR, Gradert $T L$, Hassenbusch SJ. Continuous intrathecal infusion of hydromorphone: safety in the sheep model and clinical implications. Pain Med 2004; 5: 14-25.

26. Mironer $Y$, Grumman S. Experience with alternative solutions in intrathecal treatment of chronic nonmalignant pain. Pain Digest 1999; 9: 299-302.

27. Du Pen $S, D$ u Pen A, Hillyer J. Intrathecal hydromorphone for intractable nonmalignant pain: a retrospective study. Pain Med 2006; 7 : 10-5.

28. Deer T, Krames ES, Hassenbusch SJ, et al. Polyanalgesic consensus conference 2007: recommendations for the management of pain by intrathecal (intraspinal) drug delivery: report of an interdisciplinary expert panel. Neuromodulation 2007; 10: 300-28. 